\title{
Fractal analysis of agricultural nozzles spray
}

\author{
Francisco Agüera ${ }^{1}{ }^{*}$, David Nuyttens ${ }^{2}$, Fernando Carvajal ${ }^{1}$, Julián Sánchez-Hermosilla ${ }^{1}$
}

'Universidad de Almería/Escuela de Ingeniería - Depto. de Ingeniería Rural - Ctra. Sacramento s/n - 04120 - La Cañada de San Urbano Almería - España.

${ }^{2}$ Institute for Agricultural and Fisheries Research (ILVO)/ Technology \& Food Science Unit - Agricultural Engineering, Burg. Van Gansberghelaan,

115 - 9820 - Merelbeke - Belgium.

*Corresponding author <faguera@ual.es>

Edited by: José Euclides Stipp Paterniani
ABSTRACT: Fractal scaling of the exponential type is used to establish the cumulative volume (V) distribution applied through agricultural spray nozzles in size $\mathrm{x}$ droplets, smaller than the characteristic size $X$. From exponent $d$, we deduced the fractal dimension $\left(D_{f}\right)$ which measures the degree of irregularity of the medium. This property is known as 'self-similarity'. Assuming that the droplet set from a spray nozzle is self-similar, the objectives of this study were to develop a methodology for calculating a $D_{f}$ factor associated with a given nozzle and to determine regression coefficients in order to predict droplet spectra factors from a nozzle, taking into account its own $D_{f}$ and pressure operating. Based on the iterated function system, we developed an algorithm to relate nozzle types to a particular value of $D_{f}$. Four nozzles and five operating pressure droplet size characteristics were measured using a Phase Doppler Particle Analyser (PDPA). The data input consisted of droplet size spectra factors derived from these measurements. Estimated $D_{f}$ values showed dependence on nozzle type and independence of operating pressure. We developed an exponential model based on the $D_{f}$ to enable us to predict droplet size spectra factors. Significant coefficients of determination were found for the fitted model. This model could prove useful as a means of comparing the behavior of nozzles which only differ in not measurable geometric parameters and it can predict droplet spectra factors of a nozzle operating under different pressures from data measured only in extreme work pressures.

Keywords: pesticides application, modeling
Received June 09, 2010

Accepted September 29, 2011 description of highly irregular and heterogeneous media. Fractal theory postulates an intrinsic symmetry law underlying the apparent disorder of these media, which consists of the repetition of the disorder itself over a certain range of scales. This property is called 'self-similarity' and objects or sets which exhibit this property are referred to as 'fractals'.

In the field of agricultural nozzles, fractal concepts and ideas have been used by Agüera et al. (2006), to predict droplet size spectra factors.

Scaling laws of the type shown below, have been applied to the cumulative number of soil aggregates (Perfect et al., 1992)

$N_{x>X} \approx X^{-D f}$

where: $N_{x>X}$ is the cumulative number of size $x$ aggregates greater than a characteristic size $X$. Exponent $\mathrm{D}_{f^{\prime}}$ called 'fractal dimension', measures the degree of irregularity of the medium. These laws are based on the assumption that the behavior of certain soil properties is invariable regardless of the scale used for their study. Thus, Eghball et al. (1993) quantified changes in soil structure by detecting changes in the $\mathrm{D}_{f}$ values associated with them.

Taking expression (1) into account, the numbersize distribution can be inferred from the volume-size distribution function $V(x<X)$ of the cumulative volume of aggregates with a characteristic size lower than $X$. Thus, if spray droplets are grouped into different classes according to their sizes, droplet size spectra function shape (droplet diameter vs. accumulated volume fraction) at this scale is defined by the volume in each of these classes. If the scale in one of these classes is 
changed, new and different classes will appear and it might be expected that that the initial structure will be repeated, in other words: the proportion of volume in each class will agree with the above scale. Fractal ideas could be applied to the description of such distributions based on the scale: 'invariable behavior of spray properties'. If self-similarity is accepted for droplet sets, this process could be repeated at different scales.

If we accept the assumptions of constant density and spherical shape for droplet spray, the law scale expressed in (1) may be related to

$V(x<X) \approx X^{d}$

where: the relation between the exponents is $d=3-\mathrm{D}_{f}$ (Tyler and Wheatcraft, 1992).

Our study, therefore, had two objectives: i) to develop a methodology for calculating a $\mathrm{D}_{f}$ factor associated with a given nozzle and independent of operating conditions; and ii) to determine regression coefficients in order to predict droplet spectra factors $\left(\mathrm{D}_{\mathrm{v} 0.1^{\prime}}, \mathrm{D}_{\mathrm{v} 0.5^{\prime}}\right.$ and $\mathrm{D}_{\mathrm{v} 0.9}$ ) from a nozzle, taking into account its own $\mathrm{D}_{f}$ and pressure operating conditions.

\section{Materials and Methods}

Four nozzle types widely used in agriculture were tested: i) Teejet DG 11002 (Spraying Systems Co., Wheaton, Il), a drift guard even flat fan nozzle, which we will refer to here as 'DG-110'; ii)Teejet XR-11001 (Spraying Systems Co., Wheaton, Il), an extended range flat fan nozzle, hereafter referred to as 'XR-110'; iii) Teejet TXA 8001 (Spraying Systems Co., Wheaton, Il), a hollow cone nozzle, to which we will refer in the text as 'TXA-80'; and iv) Teejet TP-9501 E (Spraying Systems Co., Wheaton, Il), an even flat fan nozzle, hereafter referred to simply as 'TP-9501'. These nozzles are widely used in the greenhouse crop-production system in the South-East of Spain, but the methodology described in this paper could be applied to any nozzle at any operating pressure. All four nozzles were tested at five pressure levels $(0.2,0.4,0.6,0.8$ and $1 \mathrm{MPa})$ with three replications for each pressure. This makes a total of $5 \times 3 \times 4$ $=60$ measurements. These data were obtained using a Phase Doppler Particle Analyser (PDPA).

The PDPA laser was an Aerometrics PDPA onedimensional system. All measurements were carried out by spraying water with a temperature of $20{ }^{\circ} \mathrm{C}$. Environmental conditions were kept constant at $20{ }^{\circ} \mathrm{C}$ and a relative humidity of $60-70 \%$. The nozzle was positioned $0.50 \mathrm{~m}$ above the measuring point of the PDPA. To enable the whole of the spray cloud to be sampled, the nozzle was mounted on a transporter which allowed to move it in a transverse range of $1.5 \times 1.0 \mathrm{~m}$, and $\Delta \mathrm{x}$ and $\Delta y$ of $0.1 \mathrm{~m}$. Details of this instrument and measurement protocol can be found in Nuyttens et al. (2007).

The data sets derived from these measurements and used in the present study were 20 values of droplet size spectra factors $\left(\mathrm{D}_{\mathrm{v} 0.05}, \mathrm{D}_{\mathrm{v} 0.1}, \mathrm{D}_{\mathrm{v} 0.15}, \ldots, \mathrm{D}_{\mathrm{v} 0.9}, \mathrm{D}_{\mathrm{v} 0.95}, \mathrm{D}_{\mathrm{v} 1}\right)$ for each nozzle, pressure and repetition.

$\mathrm{D}_{f}$ was calculated in two ways. Firstly, as data corresponding to droplet diameter were available from each experiment, fractal dimension for each experiment was calculated, taking into account equation (1), using the diameter droplets measured with the PDPA instrument for each nozzle, repetition and operating pressure. To do so, we arranged every data set in ascending order from minimum to maximum diameter. We then grouped each set into sub-sets of 500 droplets and their average diameter was calculated, thereby obtaining a set of average diameters. $\mathrm{D}_{f}$ of every set was computed, taking into account equation (1), which can be particularized with Mandelbrot's (1982) expression for self-similar sets

$N_{x>X}=k_{1} \times X^{-\mathrm{D} f}$

where $k_{1}$ is a constant. This can be rewritten as

$\log \left(N_{x>X}\right)=\log \left(k_{1}\right)-\mathrm{D}_{f} \times \log (X)$

Therefore, $\mathrm{D}_{f}$ will be derived from the regression coefficient of the linear regression fitted between $\log \left(N_{x>X}\right)$ and $\log (X)$, being $N_{x>X}$ the cumulative number of diameter $x$ droplets greater than a characteristic average diameter $X$ of a sub-set containing 500 droplets. This calculation was carried out considering all operating pressure $\left(D_{f r}\right)$ and considering only the extreme operating pressure $\left(\mathrm{D}_{f r 1}\right)$.

Secondly, $\mathrm{D}_{f}$ was estimated as follows: let $\mathrm{I}_{1}=\left[\mathrm{D}_{\min }\right.$,

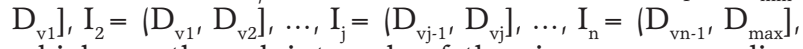
which are the sub-intervals of the sizes corresponding to the $\mathrm{n}$ droplet size spectra factor, where $\mathrm{D}_{\min }$ and $\mathrm{D}_{\max }$ are the minimum and maximum droplet diameter, respectively. Thus, the whole range of droplet diameter is $\mathrm{I}=\left[\mathrm{D}_{\text {min' }}, \mathrm{D}_{\text {max }}\right]$. In addition, $q_{1}, q_{2}, \ldots, q_{\mathrm{j}}, \ldots, q_{\mathrm{n}}$ are the relative volume proportions or probabilities $l q_{1}+q_{2}+$ $\ldots+q_{\mathrm{j}}+\ldots+q_{\mathrm{n}}=1$ ) of volume intervals $\mathrm{I}_{1}, \mathrm{I}_{2}, \ldots, \mathrm{I}_{\mathrm{j}}, \ldots$, $\mathrm{I}_{\mathrm{n}^{\prime}}$ respectively.

The following functions may be considered:

$$
\begin{aligned}
& \Psi_{1}=\mathrm{D}_{\text {min }}+\left(x-\mathrm{D}_{\min }\right) \times \frac{\mathrm{D}_{\mathrm{v} 1}-\mathrm{D}_{\text {min }}}{\mathrm{D}_{\text {max }}-\mathrm{D}_{\min }} \\
& \Psi_{2}=\mathrm{D}_{\mathrm{v} 1}+\left(x-\mathrm{D}_{\min }\right) \times \frac{\mathrm{D}_{\mathrm{v} 2}-\mathrm{D}_{\mathrm{v} 1}}{\mathrm{D}_{\max }-\mathrm{D}_{\min }} \\
& \Psi_{\mathrm{j}}=\mathrm{D}_{\mathrm{j}-1}+\left(x-\mathrm{D}_{\min }\right) \times \frac{\mathrm{D}_{\mathrm{vj}}-\mathrm{D}_{\mathrm{vj}-1}}{\mathrm{D}_{\text {max }}-\mathrm{D}_{\min }} \\
& \Psi_{\mathrm{n}}=\mathrm{D}_{\mathrm{n}-1}+\left(x-\mathrm{D}_{\min }\right) \times \frac{\mathrm{D}_{\max }-\mathrm{D}_{\mathrm{vn}-1}}{\mathrm{D}_{\max }-\mathrm{D}_{\min }}
\end{aligned}
$$

where: $x \in\left[\mathrm{D}_{\text {min }^{\prime}} \mathrm{D}_{\max }\right]$. In the equations 5 to $8, \Psi_{\varphi^{\prime}} \mathrm{j}=$ $\{1,2, \ldots, n\}$ are the linear functions that transform the $\left[\mathrm{D}_{\min }, \mathrm{D}_{\max }\right]$ points into $\mathrm{I}_{\mathrm{j}^{\prime}} \mathrm{j}=\{1,2, \ldots, \mathrm{n}\}$ points. The set $\left\{\Psi_{\varphi^{\prime}} ; q_{\mathrm{j}} ; \mathrm{j}=\{1,2, \ldots, \mathrm{n}\}\right\}$ is called an 'iterated function 
system' (Barnsley and Demko, 1985). By means of the similarities $\Psi_{j}$ and the volume proportions $q_{j}$ an iterated function system determines how a fractal distribution reproduces its structure at different scales. Figure 1 shows a graphical representation of the performance of the iterated functions system: each function $\Psi_{\varphi^{\prime}}$ with $\mathrm{j}=$ $\{1,2, \ldots, n\}$ transforms values of the whole range of drop diameters $\left[D_{\min }, D_{\max }\right]$ into points of the ranges $I_{j}$, with $j=$ $\{1,2, \ldots, n\}$. For example, function $\Psi_{1}$ transform the values of $\left[\mathrm{D}_{\min }, \mathrm{D}_{\max }\right]$ into values of $\mathrm{I}_{1}$, taking into account equation (1), and so for the rest of $\Psi_{\varphi}$ s. Furthermore, the probability of use the function $\Psi_{j}$ is $q_{j}$, which is the volume fraction accumulated in the range $I_{j}$.

This second method to estimate the fractal dimension has been developed because usually, data supplied by the nozzle manufacturer is the volumetric droplet size distribution. So, available data are $\mathrm{D}_{\mathrm{v}}$ 's instead of cloud droplet diameters. Using fractal geometry, an algorithm can be defined to obtain $\mathrm{D}_{f}$ of a nozzle (Elton, 1987; Turcotte, 1992): i) take any value $x_{0}$ of $\left[\mathrm{D}_{\min }, \mathrm{D}_{\max }\right]$; ii)take a random number $\mathrm{j}, \mathrm{j}=\{1,2, \ldots, \mathrm{n}\}$, being $q_{\mathrm{j}}=\left\{q_{1}, q_{2}\right.$ $\left.\ldots, q_{\mathrm{n}}\right\}$ their respective probabilities, and compute $x_{1}=$ $\Psi_{\mathrm{j}}\left(x_{0}\right)$; and iii) repeat step 2 taking $x_{1}$ to compute the next value. In this way, a set $S=\left\{x_{1}, x_{2}, \ldots, x_{m}\right\}$ is obtained.

This is not a set of droplets, instead these elements allow us to obtain the droplet diameter versus the cumulative volume fraction function and from this function we can then obtain the droplet size distribution, as follows: if $g$ is the number of $x^{\prime} s$ values that belong to any

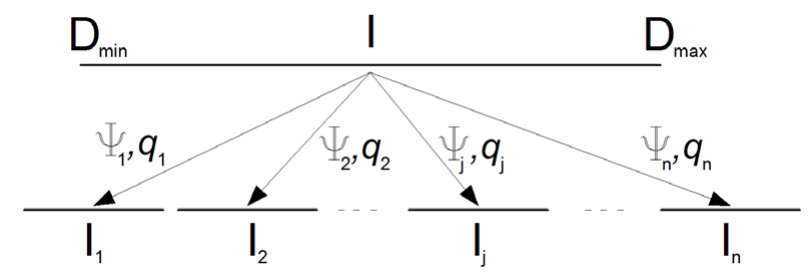

Figure 1 - Graphical representation of the performance of the iterated functions system: functions $\Psi_{\varphi}, j=\{1,2, \ldots, n\}$ transform points of the whole range of drop size $I=\left[D_{\min }, D_{\max }\right]$ into points of the ranges $I_{i}, j=\{1,2, \ldots, n\}$. The probability of use a function $\Psi_{\varphi}$ is $q_{j}$. interval $\mathrm{I}_{\mathrm{j}}$, the ratio $\mathrm{g} / \mathrm{m}$ approaches the relative volume of the interval $I_{j}$ as the number of iterations $m$ goes to infinite. For example, if droplet size spectra factors measurements were $\mathrm{D}_{\mathrm{v} 0.1}=147, \mathrm{D}_{\mathrm{v} 0.5}=464$, and $\mathrm{D}_{\mathrm{v} 0.9}=1000$ $\mu \mathrm{m}$ and the elements generated by the algorithm corresponding to this test $\left\{x_{1}, x_{2}, \ldots, x_{m}\right\}$ are sorted by 'size', there will be $0.1 \times \mathrm{m}$ elements with a size equal or less than $147\left(\mathrm{D}_{\mathrm{v} 0.1}\right) ; 0.5 \times \mathrm{m}$ elements with a size equal or less than $464\left(\mathrm{D}_{\mathrm{v} 0.5}\right)$; and $0.9 \times \mathrm{m}$ elements with a size equal or less than $1000\left(\mathrm{D}_{\mathrm{v} 0.9}\right)$.

$\mathrm{D}_{f}$ of this set will be computed taking into account equation (2), which can be particularized as follows

$N_{x<X}=k \times X^{d}$

where $\mathrm{k}$ is a constant. It can be rewritten as

$\log \left(N_{x<X}\right)=\log (k)+d \times \log (X)$

Therefore, $\mathrm{D}_{f}=3-\mathrm{d}$ will be derived from the regression coefficient of the linear regression fitted between $\log \left(N_{x<X}\right)$ and $\log (X)$.

The number $\mathrm{m}$ of elements generated in each application of this algorithm were 10000, and the initial value for $x\left(x_{0}\right)$ was $D_{v 0.9}$. Similar results could be expected if $m \geq 3000$ and $x_{0}$ takes any value of $\left[D_{\min }, D_{\max }\right]$ (Taguas et al., 1999).

A total of ten iterated function systems differing in number and combination of droplet size spectra factors (Table 1) were used to estimate $\mathrm{D}_{f}\left(\mathrm{D}_{f e}\right)$ in order to study the accuracy of the algorithm described when applied to each of these combinations. Fractal dimension was also estimated in two ways: 1) by taking into account all operating pressures $\left(\mathrm{D}_{f e}\right)$; and 2$)$ by taking into account only the extreme operating pressure of 2 and 10 $\operatorname{bar}\left(\mathrm{D}_{f e 1}\right)$.

The size frequency distribution of every set $\mathrm{S}_{\mathrm{q}}=$ $\left\{\mathrm{x}_{1}, \mathrm{x}_{2}, \ldots, \mathrm{x}_{\mathrm{m}}\right\}$ was calculated by dividing the size range into 20 classes (Steel and Torrie, 1980). The number of elements in each class was counted and the linear regression between $\log (\mathrm{N}, \mathrm{x})$ and $\log (\mathrm{x})$ was carried out using the droplet size spectra factors corresponding to

Table 1 - Droplet size spectra factor combinations taken into account when applying the algorithm based on the iterated function system. A cross indicates that the value concerned has been considered. In the first row, $\mathrm{D}_{v x}$ indicate droplet size spectra factors corresponding with $\mathrm{x} \%$.

\begin{tabular}{|c|c|c|c|c|c|c|c|c|c|c|c|c|c|c|c|c|c|c|c|c|}
\hline Combination & $D_{v 0.05}$ & $D_{v 0.1}$ & $\mathrm{D}_{\mathrm{v} 0.15}$ & $\mathrm{D}_{\mathrm{v} 0.2}$ & $\mathrm{D}_{\mathrm{v} 0.25}$ & $\mathrm{D}_{\mathrm{v} 0.3}$ & $\mathrm{D}_{\mathrm{v} 0.35}$ & $\mathrm{D}_{\mathrm{v} 0.4}$ & $\mathrm{D}_{\mathrm{v} 0.45}$ & $\mathrm{D}_{\mathrm{v} 0.5}$ & $\mathrm{D}_{\mathrm{v} .55}$ & $\mathrm{D}_{\mathrm{v} 0.6}$ & $\mathrm{D}_{\mathrm{v} 0.65}$ & $\mathrm{D}_{\mathrm{v} 0.7}$ & $\mathrm{D}_{\mathrm{v} 0.75}$ & $\mathrm{D}_{\mathrm{v} 0.8}$ & $\mathrm{D}_{\mathrm{v} 0.85}$ & $\mathrm{D}_{\mathrm{v} 0.9}$ & $\mathrm{D}_{\mathrm{v0.95}}$ & $D_{\mathrm{v} 1}$ \\
\hline 1 & $x$ & $x$ & $x$ & $x$ & $x$ & $x$ & $x$ & $x$ & $x$ & $x$ & $x$ & $x$ & $x$ & $x$ & $x$ & $x$ & $x$ & $x$ & $x$ & $x$ \\
\hline 2 & & $x$ & & & & & & & & $x$ & & & & & & & & $x$ & & \\
\hline 3 & $X$ & $X$ & & & & & & & & $X$ & & & & & & & & $X$ & $X$ & \\
\hline 4 & & $X$ & $X$ & & & & & & & $X$ & & & & & & & $x$ & $X$ & & \\
\hline 5 & & $x$ & $x$ & & $x$ & & & & & $x$ & & & & & $x$ & & $x$ & $x$ & & \\
\hline 6 & $x$ & $x$ & & & $x$ & & & & & $x$ & & & & & $x$ & & & $x$ & $x$ & \\
\hline 7 & $x$ & $x$ & $x$ & & & & & & & $x$ & & & & & & & $x$ & $x$ & $x$ & \\
\hline 8 & $x$ & $x$ & $x$ & & & $x$ & & & & $x$ & & & & $x$ & & & $x$ & $x$ & $x$ & \\
\hline 9 & $x$ & $x$ & $x$ & & $x$ & & $x$ & & & $x$ & & & $x$ & & $x$ & & $x$ & $x$ & $x$ & \\
\hline 10 & $x$ & $x$ & $x$ & $x$ & & & & & & $x$ & & & & & & $x$ & $x$ & $x$ & $x$ & \\
\hline
\end{tabular}


extreme operating pressures (2 and 10 bar). This task was carried out by a computer program developed by the authors using Visual Basic 6.0.

Droplet size spectra factors were predicted using an exponential function as follows:

$\mathrm{D}_{\mathrm{vh}}=\exp \left(\mathrm{a}+\mathrm{b} \times \mathrm{p}+\mathrm{c} \times \mathrm{D}_{f e 1}\right)$

where: $\mathrm{D}_{\mathrm{vh}}$ can be $\mathrm{D}_{\mathrm{v} 0.1}, \mathrm{D}_{\mathrm{v} 0.5}$ or $\mathrm{D}_{\mathrm{v} 0.9}(\mu \mathrm{m})$ of a given nozzle, $\mathrm{p}$ is the operating pressure (bar), and $\mathrm{D}_{f e 1}$ is the fractal dimension, estimated as described above ('A fractal approach to droplet size distribution' section). The data used to carry out this regression were those from operating pressures of $0.4,0.6$ and $0.8 \mathrm{Mpa}$, which were not used to estimate $\mathrm{D}_{f e 1}$.

\section{Results and Discussion}

For a given nozzle, differences between functions representing each operating pressure presented no effect (Figure 2). Nevertheless, the DG-110 (Figure 2a) behavior at 0.8 and $1 \mathrm{MPa}$ was very similar, and was quite different from its behavior at other pressures. Furthermore, the TXA-80 nozzle (Figure 2c), shows differences with different operating pressures. In general, a higher spray pressure corresponded to a smaller droplet size spectrum. These results are similar to those found by Womac (2001) working with nozzles under a range of pressures.
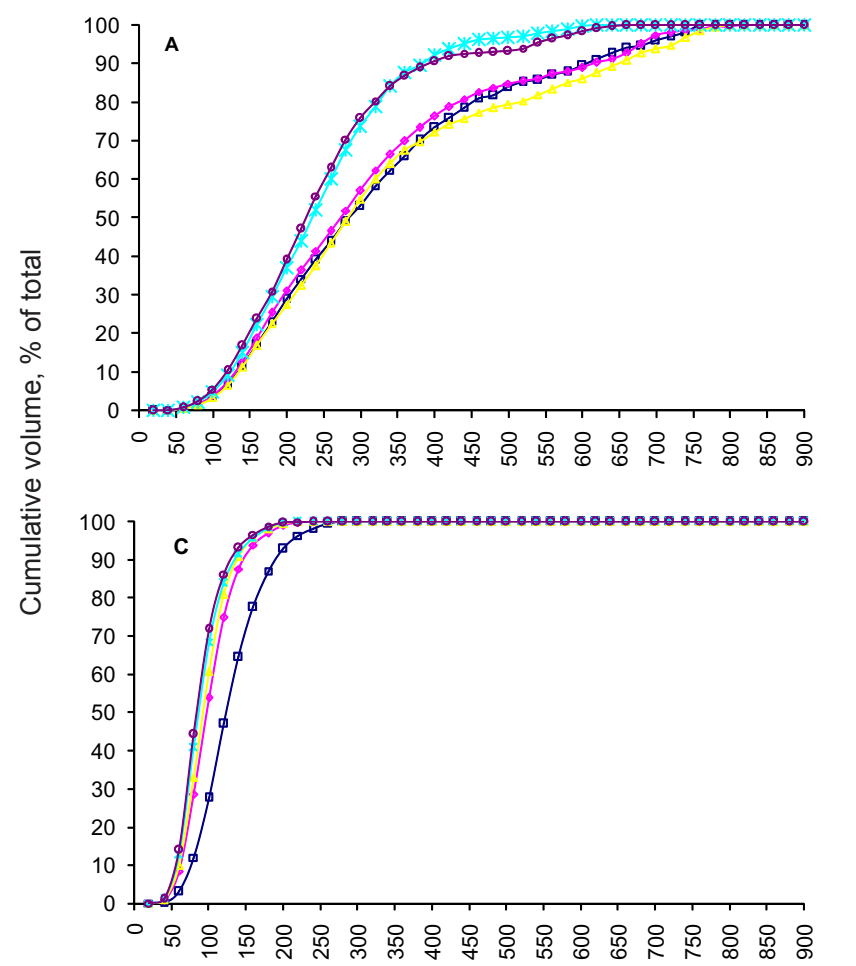

Furthermore, when the nozzles were compared, the cumulative volumetric droplet size distributions were quite different. All these affirmations about the cumulative droplet size distribution are based on an ANOVA carried out comparing $\mathrm{D}_{\mathrm{v} 10}, \mathrm{D}_{\mathrm{v} 25}, \mathrm{D}_{\mathrm{v} 50,} \mathrm{D}_{\mathrm{v} 75}$ and $\mathrm{D}_{\mathrm{v} 90}$ of each nozzle working at $0.2,0.4,0.6,0.8$ and $1 \mathrm{MPa}$ (data not presented). Similarity cumulative volumetric droplet size distribution behavior was related with nozzle type: TP-9501 and XR-110 are flat fan nozzles whereas DG110 is a drift guard flat fan and TXA-80 is a hollow cone nozzle. Droplet sizes vary from a few micrometers up to some hundreds of micrometers depending on the nozzle type. Cone nozzle (TXA-80), produced the finest droplet size spectrum, followed by flat fan nozzles (TP-9501 and XR-110) and drift guard nozzle (DG-110). Nuyttens et al. (2007) observed the same behavior for these kinds of nozzles under a range of pressures.

Fractal dimension, calculated taking into account equation (1), can be considered the 'real $\mathrm{D}_{f}^{\prime}$ given that it is derived from the droplet diameter measurements from each experiment. Figure 3 shows an example of relationship between $\log (\mathrm{D})$ and $\log \left(N_{\mathrm{d}>\mathrm{D}}\right)$, and the fitted line for each tested nozzle. To clarify these graphics, only 10 $\%$ approximately of data of each nozzle have been plotted. Anyway, the regressions have taken into account the whole data set. Although data had not a perfect straight tendency, which means no perfect fractal behavior, all studied cases (nozzle, operation pressure and replica-
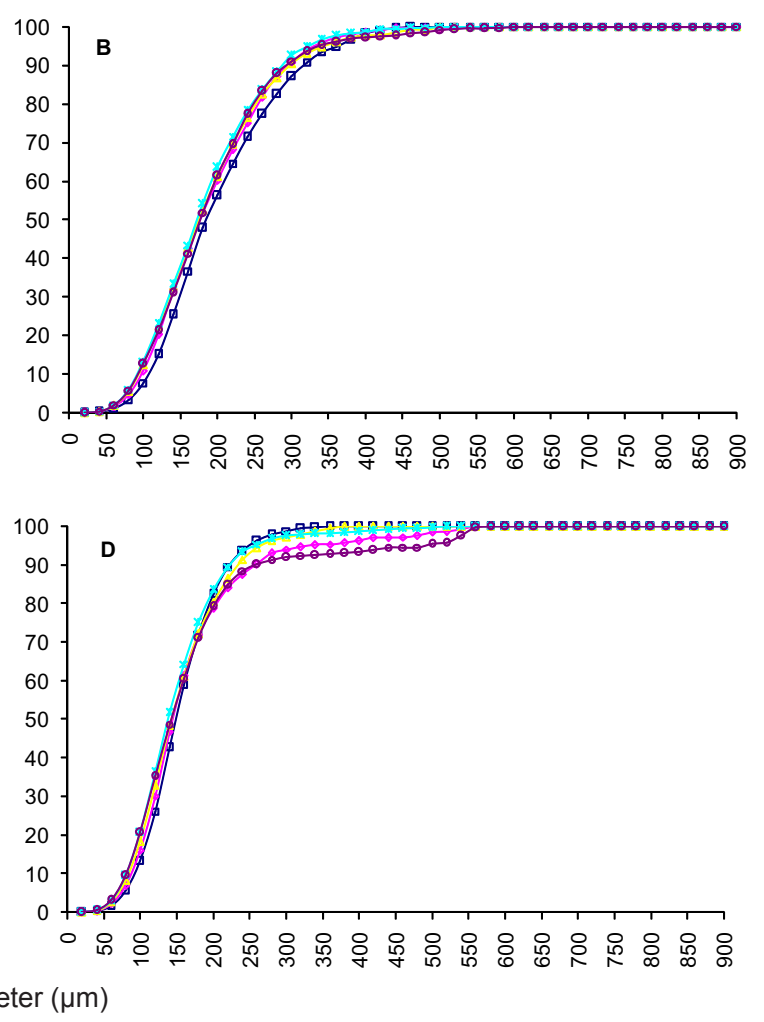

Figure 2 - Cumulative volumetric droplet size distribution for the four nozzles tested (a: DG-110, b: XR-110, c: TXA-80, d: TP-9501), and five operating pressures ( $\square: 0.2 \mathrm{MPa}, \diamond: 0.4 \mathrm{MPa}, \Delta: 0.6 \mathrm{MPa}, *: 0.8 \mathrm{MPa}, \circ: 1 \mathrm{MPa}$ ). 

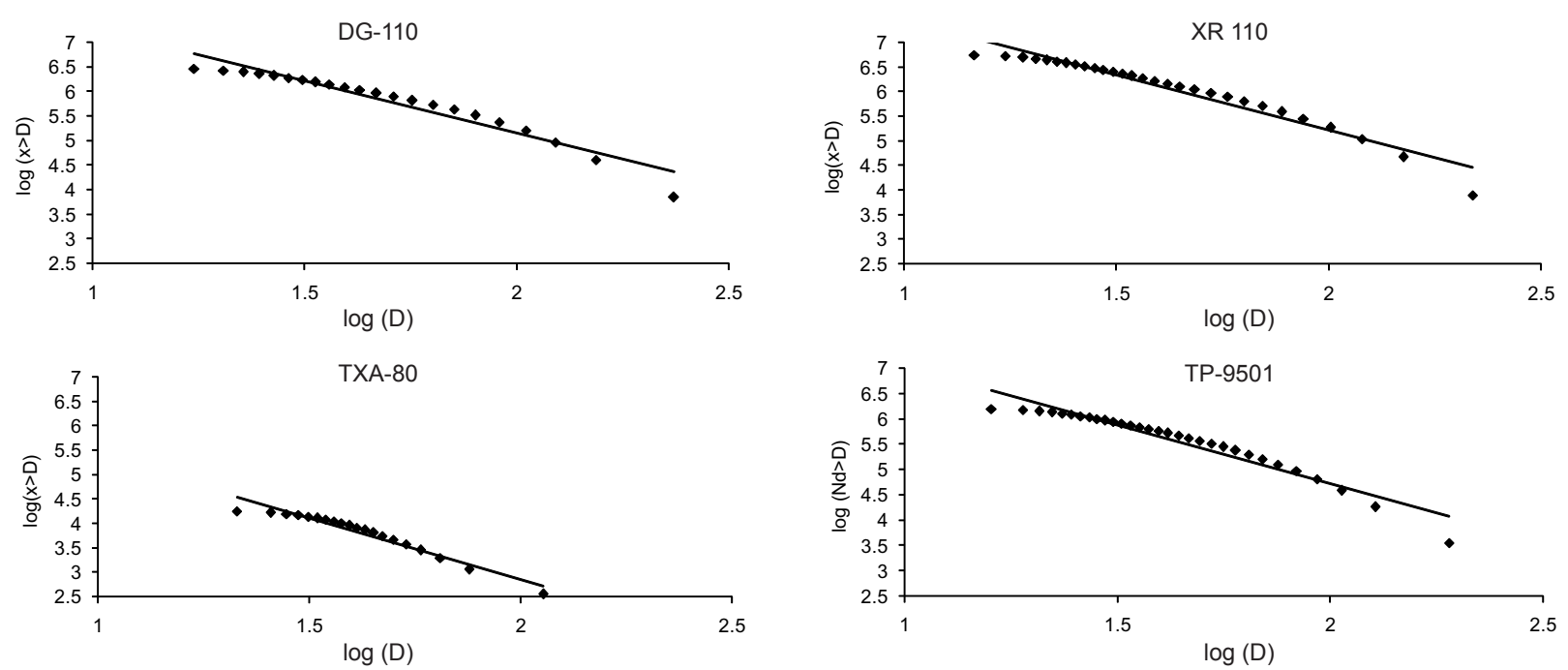

Figure 3 - Examples of relationship between $\log (D)$ and $\log \left(N_{\mathrm{d}>\mathrm{D}}\right)$, and the fitted line for each tested nozzle. For DG-110 nozzle: $\log \left(N_{\mathrm{d}>\mathrm{D}}\right)=9.40-2.13 \times$ $\left.\log (D), r^{2}=0.93\right)$, operating pressure: $0.8 \mathrm{MPa}$; for XR-1 10 nozzle: $\left.\log \left(N_{d>0}\right)=9.70-2.24 \times \log (D), r^{2}=0.95\right)$, operating pressure: $0.2 \mathrm{MPa}$; for TXA-80 nozzle: $\left.\log \left(N_{\mathrm{d}>\mathrm{D}}\right)=7.87-2.50 \times \log (\mathrm{D}), \mathrm{r}^{2}=0.95\right)$, operating pressure: $0.8 \mathrm{MPa}$; for TXA-80 nozzle: $\left.\log \left(N_{\mathrm{d}>\mathrm{D}}\right)=9.36-2.32 \times \log (\mathrm{D}), \mathrm{r}^{2}=0.93\right)$, operating pressure: $0.4 \mathrm{MPa}$. D is the droplet diameter $(\mu \mathrm{m})$ and $N_{\mathrm{d}>\mathrm{D}}$ is the cumulative number of size d droplets greater than a characteristic diameter.

tion) shown similar behavior: the relationship between variables was correlated $(p<0.01)$. Furthermore, all regression coefficients indicate that the model as fitted explained more than $90 \%$ of the variability in dependent variable $\left(\log \left(N_{\mathrm{d}>\mathrm{D}}\right)\right)$.

Table 2 shows the average 'real fractal dimension' for each nozzle, operating pressure and repetitions studied, which have been calculated taking into account measured droplet diameters. The $\mathrm{D}_{f r}$ column shows the $\mathrm{D}_{f}$ average calculated based on the values corresponding to the five operating pressures, while the $\mathrm{D}_{f r}$ column shows the $\mathrm{D}_{f}$ average calculated from the extreme pressures (0.2 and $1 \mathrm{MPa})$. Since $\mathrm{D}_{f}$ is not a measurable physical magnitude, we have decided to report these values to an accuracy of four decimal places, although we have not looked at the effect of decimal places on our results.

Values shown in each row are different $(p<0.05)$, whereas the values shown in each column are not different $(p>0.05)$ (Table 2). Thus, the $\mathrm{D}_{f}$ calculated in this way and associated with nozzles, results in values which are independent of operating pressure. Similar results were found by Agüera et al. (2006) when working with hydraulic nozzles with variable geometry.

Table 3 shows the $\mathrm{D}_{f e}$ for every nozzle and $\mathrm{D}_{\mathrm{v}}$ combination (Table 1) when the algorithm based on iterated function systems described as the second method in 'Calculating the fractal dimension' section was applied. The column labeled 'sd' indicates the standard deviation of $\mathrm{D}_{f e}$ derived from the five operating pressures and the three repetitions, whereas $\mathrm{r}^{2}{ }_{\max }$ and $\mathrm{r}^{2}{ }_{\min }$ indicate the maximum and minimum regression coefficients of linear regression between $\log \left(N_{x<X}\right)$ and $\log (X)$. Column $\mathrm{D}_{f e 1}$ represents the fractal dimension for every nozzle, considering data from operating pressures of 0.2 and 1
Table $2-D_{f}$ (fractal dimension) for each nozzle and each pressure, calculated from droplets population, taking into account eq. (1). $D_{f r}$ is the fractal dimension calculated as the average of fractal dimensions from the five operating pressures and $D_{f r l}$ is the fractal dimension calculated as the average of fractal dimensions from extreme operating pressures ( 0.2 and $1 \mathrm{MPa})$.

\begin{tabular}{|c|c|c|c|c|c|c|c|}
\hline \multicolumn{8}{|c|}{$D_{f}$} \\
\hline \multicolumn{6}{|c|}{ Operating pressure (bar) } & \multirow[b]{2}{*}{$D_{t r}$} & \multirow[b]{2}{*}{ Dir1 } \\
\hline nozzle & 2 & 4 & 6 & 8 & 10 & & \\
\hline DG-110 & 2.1679 & 2.1558 & 2.1419 & 2.1268 & 2.1860 & 2.1557 & 2.1769 \\
\hline XR-110 & 2.2437 & 2.2536 & 2.3160 & 2.3036 & 2.2638 & 2.2762 & 2.2538 \\
\hline TXA-80 & 2.5169 & 2.5511 & 2.5665 & 2.5350 & 2.5867 & 2.5512 & 2.5518 \\
\hline TP-9501 & 2.3126 & 2.3204 & 2.3424 & 2.3537 & 2.3621 & 2.3382 & 2.3373 \\
\hline
\end{tabular}

$\mathrm{MPa}$, and $\mathrm{D}_{\mathrm{v}}$ combinations when the algorithm based on iterated function was applied. For a given nozzle and column, $\mathrm{D}_{f e}$ or $\mathrm{D}_{f e 1}$ values followed by the same letter are not different $(p<0.05) . \mathrm{D}_{f e}$ and $\mathrm{D}_{f e 1}$ estimated taking into account $\mathrm{D}_{\mathrm{v}}$ combination 1 can be regarded as being the nearest to the 'real $\mathrm{D}_{f}$ ' shown in Table 2, given that the $20 \mathrm{D}_{\mathrm{v}}$ values were used with the iterate function system. In fact, the values shown in columns $\mathrm{D}_{f r}$ or $\mathrm{D}_{f r 1}$ of Table 2 are not different $(p<0.05)$ from those of Table 3 corresponding to combination 1. Relationship between $\log \left(N_{x<X}\right)$ and $\log (X)$ were correlated $(p<0.01)$. Furthermore, all regression coefficients indicate that the model as fitted explained the variability in dependent variable $\left(\log \left(N_{\mathrm{d}>\mathrm{D}}\right)\right)$ between 0.826 (observed in the TXA-80 nozzle) and 0.979 (observed in the DG-110 nozzle).

$\mathrm{D}_{\mathrm{v}}$ combination numbers 2,4 and 5 yielded $\mathrm{D}_{f e}$ values which were different from those of the remaining $D_{v}$ combinations. Combination 2 includes only three $\mathrm{D}_{\mathrm{v}}$ values: $\mathrm{D}_{\mathrm{v} 0.1}, \mathrm{D}_{\mathrm{v} 0.5}$ and $\mathrm{D}_{\mathrm{v} 0.9}$, which are probably not 
Table 3 - Estimated $D_{f}$ (fractal dimension) for every nozzle and $D_{v}$ (droplet size spectra factors) combinations when the algorithm based on iterated function was applied. The sd column indicates the standard deviation of $D_{f e}$ (fractal dimension derived from the five operating pressures and the three repetitions). Columns $r^{2}$ max and $r_{\text {min }}^{2}$ indicate the maximum and minimum coefficients of determination of linear regression between $\log \left(N_{x<x}\right)$ (being $N_{x>x}$ the cumulative number of diameter $x$ droplets greater than a characteristic average diameter $X$ of a sub-set containing 500 droplets) and $\log (X)$ (being $X$ the average diameter of a sub-set containing 500 droplet), respectively. Column $D_{\text {fel }}$ represents fractal dimension for every nozzle, taking into account data from operating pressure of 0.2 and $1 \mathrm{MPa}$, and $\mathrm{D}_{v}$ (droplet size spectra factors) combinations when the algorithm based on iterated function was applied. For a given nozzle and column, $D_{f e}$ or $D_{f e}$ values followed by the same letter are not different $(p<0.05)$.

\begin{tabular}{|c|c|c|c|c|c|c|}
\hline nozzle & $\begin{array}{c}D_{v} \\
\text { combination }\end{array}$ & $\mathrm{D}_{\mathrm{fe}}$ & $\mathrm{sd}$ & $\mathrm{r}_{\text {min }}^{2}$ & $\mathrm{r}_{\text {max }}^{2}$ & $D_{f e 1}$ \\
\hline DG-110 & 1 & $2.2005^{a}$ & 0.0558 & 0.899 & 0.970 & $2.1842^{\mathrm{a}}$ \\
\hline DG-110 & 2 & $2.0782^{b}$ & 0.0809 & 0.906 & 0.975 & $2.0488^{b}$ \\
\hline DG-110 & 3 & $2.2079^{a}$ & 0.0676 & 0.890 & 0.967 & $2.1868^{a}$ \\
\hline DG-110 & 4 & $2.0726^{b}$ & 0.0744 & 0.909 & 0.975 & $2.0553^{\mathrm{b}}$ \\
\hline DG-110 & 5 & $2.0815^{b}$ & 0.0738 & 0.915 & 0.979 & $2.0650^{\mathrm{b}}$ \\
\hline DG-110 & 6 & $2.2022^{\mathrm{a}}$ & 0.0581 & 0.884 & 0.963 & $2.1792^{\mathrm{a}}$ \\
\hline DG-110 & 7 & $2.2047^{a}$ & 0.0560 & 0.884 & 0.967 & $2.1951^{\mathrm{a}}$ \\
\hline DG-110 & 8 & $2.2006^{a}$ & 0.0563 & 0.888 & 0.969 & $2.1798^{a}$ \\
\hline DG-110 & 9 & $2.1974^{a}$ & 0.0541 & 0.888 & 0.967 & $2.1845^{\mathrm{a}}$ \\
\hline DG-110 & 10 & $2.2006^{a}$ & 0.0559 & 0.880 & 0.972 & $2.1788^{a}$ \\
\hline XR-110 & 1 & $2.2439^{a}$ & 0.0865 & 0.864 & 0.977 & $2.2695^{\mathrm{a}}$ \\
\hline XR-110 & 2 & $2.1137^{c}$ & 0.1248 & 0.860 & 0.973 & $2.1526^{a}$ \\
\hline XR-110 & 3 & $2.2398^{\mathrm{a}, \mathrm{b}}$ & 0.0837 & 0.826 & 0.975 & $2.2591^{\mathrm{a}}$ \\
\hline XR-110 & 4 & $2.1264^{b, c}$ & 0.1250 & 0.861 & 0.977 & $2.1709^{a}$ \\
\hline XR-110 & 5 & $2.1240^{c}$ & 0.1173 & 0.875 & 0.977 & $2.1547^{\mathrm{a}}$ \\
\hline XR-110 & 6 & $2.2426^{a}$ & 0.0938 & 0.846 & 0.976 & $2.2652^{\mathrm{a}}$ \\
\hline XR-110 & 7 & $2.2413^{a}$ & 0.0823 & 0.836 & 0.977 & $2.2644^{\mathrm{a}}$ \\
\hline XR-110 & 8 & $2.2405^{\mathrm{a}, \mathrm{b}}$ & 0.0865 & 0.858 & 0.976 & $2.2631^{\mathrm{a}}$ \\
\hline XR-110 & 9 & $2.2400^{\mathrm{a}, \mathrm{b}}$ & 0.0841 & 0.861 & 0.978 & $2.2659^{a}$ \\
\hline XR-110 & 10 & $2.2439^{a}$ & 0.0846 & 0.844 & 0.977 & $2.2670^{\mathrm{a}}$ \\
\hline TXA-80 & 1 & $2.4440^{a}$ & 0.0270 & 0.935 & 0.972 & $2.4424^{a}$ \\
\hline TXA-80 & 2 & $2.3322^{\mathrm{b}}$ & 0.0422 & 0.941 & 0.967 & $2.3237^{b}$ \\
\hline TXA-80 & 3 & $2.4455^{a}$ & 0.0265 & 0.930 & 0.974 & $2.4437^{a}$ \\
\hline TXA-80 & 4 & $2.3274^{b}$ & 0.0354 & 0.940 & 0.970 & $2.3208^{\mathrm{b}}$ \\
\hline TХА-80 & 5 & $2.3263^{b}$ & 0.0376 & 0.940 & 0.972 & $2.3215^{\mathrm{b}}$ \\
\hline TXА-80 & 6 & $2.4438^{a}$ & 0.0282 & 0.938 & 0.975 & $2.4461^{\mathrm{a}}$ \\
\hline TXА-80 & 7 & $2.4465^{\mathrm{a}}$ & 0.0250 & 0.934 & 0.970 & $2.4387^{a}$ \\
\hline TXA-80 & 8 & $2.4473^{a}$ & 0.0222 & 0.937 & 0.975 & $2.4393^{\mathrm{a}}$ \\
\hline TXA-80 & 9 & $2.4425^{a}$ & 0.0269 & 0.934 & 0.973 & $2.4394^{a}$ \\
\hline TXA-80 & 10 & $2.4401^{\mathrm{a}}$ & 0.0233 & 0.937 & 0.972 & $2.4340^{\mathrm{a}}$ \\
\hline TP-9501 & 1 & $2.2209^{a}$ & 0.1077 & 0.862 & 0.968 & $2.2593^{a}$ \\
\hline TP-9501 & 2 & $2.0661^{d}$ & 0.1325 & 0.831 & 0.959 & $2.1095^{\mathrm{a}}$ \\
\hline TP-9501 & 3 & $2.2155^{a}$ & 0.1095 & 0.843 & 0.964 & $2.2469^{a}$ \\
\hline TP-9501 & 4 & $2.0718^{c, d}$ & 0.1416 & 0.841 & 0.964 & $2.1173^{a}$ \\
\hline TP-9501 & 5 & $2.0761^{b, c, d}$ & 0.1361 & 0.859 & 0.965 & $2.1004^{\mathrm{a}}$ \\
\hline TP-9501 & 6 & $2.2119^{a, b}$ & 0.1136 & 0.862 & 0.967 & $2.2494^{a}$ \\
\hline TP-9501 & 7 & $2.2176^{a}$ & 0.1059 & 0.844 & 0.968 & $2.2494^{a}$ \\
\hline TP-9501 & 8 & $2.2161^{a}$ & 0.1117 & 0.867 & 0.968 & $2.2554^{a}$ \\
\hline TP-9501 & 9 & $2.2084^{a, b, c}$ & 0.1082 & 0.866 & 0.968 & $2.2429^{a}$ \\
\hline TP-9501 & 10 & $2.2229^{a}$ & 0.1111 & 0.845 & 0.966 & $2.2571^{\mathrm{a}}$ \\
\hline
\end{tabular}

enough to obtain precise $\mathrm{D}_{f}$ values. Combination 4 adds two values of $\mathrm{D}_{\mathrm{v}}: \mathrm{D}_{\mathrm{v} 0.15}$ and $\mathrm{D}_{\mathrm{v} 0.85}$, with respect to combination 2, while combination 5 adds four values with respect to combination 2: $\mathrm{D}_{\mathrm{v} 0.15}, \mathrm{D}_{\mathrm{v} 0.25}, \mathrm{D}_{\mathrm{v} 0.75}$ and $\mathrm{D}_{\mathrm{v} 0.85^{\circ}}$. All these values are between $\mathrm{D}_{\mathrm{v} 0.1}$ and $\mathrm{D}_{\mathrm{v} 0.9^{\prime}}$ situated in the constant-slope zone of the curve diameter vs. cumulative volume. Similar results were obtained for combination 3 which includes $D_{v}$ values in these areas, or combinations which include values between $\mathrm{D}_{\mathrm{v} 0.25}$ and $\mathrm{D}_{\mathrm{v} 0.75}$, except combination 1 . Nevertheless, a combination including $\mathrm{D}_{\mathrm{v} 0.1}, \mathrm{D}_{\mathrm{v} 0.5}, \mathrm{D}_{\mathrm{v} 0.9}$ and other values around $\mathrm{D}_{\mathrm{v} 0.1}$ and $\mathrm{D}_{\mathrm{v} 0.9}$ (combinations 7 and 10 ) yielded the $\mathrm{D}_{f e}$ values nearest to that yielded by combination 1 . In Table 3, combinations 1, 7 and 10 are those which are included only in group 'a'.

$\mathrm{D}_{\mathrm{v}}$ combinations are not as influential in the estimated fractal dimension as in the $\mathrm{D}_{f e}$ column: the $\mathrm{D}_{f e 1}$ value for the XR-110 and TP-9501 nozzles was independent of $\mathrm{D}_{\mathrm{v}}$ combinations, while the $\mathrm{D}_{f e 1}$ value for the DG-110 and TXA-80 nozzles does not show differences with the $\mathrm{D}_{f e}$ values (Table 3). Using iterated function systems and several combinations of soil particles size spectra factors to simulate and to test of self-similar structures for soil-size distributions, Taguas et al. (1999) found relationship between the used combination and the results accuracy.

As the $\mathrm{D}_{f e}$ values from $\mathrm{D}_{\mathrm{v}}$ combination 10 are the nearest to those from $D_{v}$ combination 1 , except for the TXA-80 nozzle, $\mathrm{D}_{f e 1}$ values from $\mathrm{D}_{\mathrm{v}}$ combination 10 were used to fit data in equation (11). Coefficients of determination and regression coefficients as determined by regression modeling of droplet size factors were:

$\mathrm{D}_{\mathrm{v} 0.1}=\exp \left(11.0534-0.01877 \times \mathrm{p}-2.82532 \times \mathrm{D}_{f e 1}\right) ; \mathrm{r}^{2}=0.8931(12)$

$\mathrm{D}_{\mathrm{v} 0.5}=\exp \left(14.0725-0.02102 \times \mathrm{p}-3.89492 \times \mathrm{D}_{\text {fe1 }}\right) ; \mathrm{r}^{2}=0.8783(13)$

$\mathrm{D}_{\mathrm{v} 0.9}=\exp \left(16.9797-0.04216 \times \mathrm{p}-4.87581 \times \mathrm{D}_{f e 1}\right) ; \mathrm{r}^{2}=0.8447(14)$

where: $\mathrm{D}_{f e 1}$ is the own fractal dimension value of each nozzle shown in Table 3 for combination $10, \mathrm{D}_{\mathrm{v} 0.1}, \mathrm{D}_{\mathrm{v} 0.5}$ or $\mathrm{D}_{\mathrm{v} 0.9}$ are $\left.\mu \mathrm{m}\right)$ and $\mathrm{p}$ is the operating pressure $(0.1 \times \mathrm{MPa})$.

Coefficients of determination which were significant $(p<0.05)$ tended to have decreasing $\mathrm{r}^{2}$ values with increasing droplet size factors, which is a similar behavior to that observed by Agüera et al. (2006) using polynomial and multilinear fitted regressions and also to that observed by Womac (2001) using a multilinear fitted regression, although in both these studies the authors found some non-significant coefficients of determination.

\section{Conclusions}

The algorithm resulted in $\mathrm{D}_{f}$ values similar to those calculated from measured droplet diameter ('real $\left.\mathrm{D}_{f}^{\prime}\right)$, regardless of the operating pressure and related to the nozzle type. $\mathrm{D}_{f}$ for a given nozzle can be calculated from two droplet size spectra measurements performed 
at extreme operating pressure $(0.2$ and $1 \mathrm{MPa})$, thus eliminating the need for droplet size measurements at intermediate operating pressures. $\mathrm{D}_{\mathrm{v} 0.11}, \mathrm{D}_{\mathrm{v} 0.5}$ and $\mathrm{D}_{\mathrm{v} 0.9}$ for the nozzles tested at 0.2 and $1 \mathrm{MPa}$ pressure can be estimated at any operating pressure from this exponential model.

\section{Acknowledgements}

This work was supported by grant P07-AGR-02995 from CICE - Junta de Andalucia (Spain), co-financed with FEDER funds of the European Union.

\section{References}

Agüera, F.; Aguilar, F.J.; Aguilar, M.A.; Carvajal, F. 2006. Atomization characteristics of hydraulic nozzles using fractal geometry. Transaction of the ASABE 49: 581-587.

ASAE Standards. 1997. S327.2: Terminology and definitions for agricultural chemical applications. ASAE Standards. 44th ed. St. Joseph, Mich.: ASAE.

Baetens, K.; Nuyttens, D.; Verboven, P.; De Schampheleire, M.; Nicolaï, B.; Ramon, H. 2007. Predicting drift from field spraying by means of a 3D computational fluid dynamics model. Computers and Electronics in Agriculture. 56: 161-173.

Baetens, K.; Ho, Q. T.; Nuyttens, D.; De Schampheleire, M.; Melese Endalew, M.; Hertog, M.; Nicolaï, B.; Ramon, H; Verboven, P. 2009. A Validated 2-D diffusion-advection model for prediction of drift from ground boom sprayers. Atmospheric Environment 43: 1674-1682.

Eghball, B.; Mielke, N.M.; Calvo, G.A.; Wilhelm, W.W. 1993. Fractal description of soil fragmentation for various tillage methods and crop sequences. Soil Science Society of America Journal 57: 1337-1341.

Elton, J. 1987. An ergodic theorem for iterated maps. Journal of Ergodic Theory and Dynamical Systems 7: 481-488.
Mandelbrot, B.B. 1982. The fractal geometry of nature. W.H. Freeman, New York, NY, USA.

Nuyttens, D.; Baetens, K.; De Schampheleire, M.; Sonck, B. 2007. Effect of nozzle type, size and pressure on spray droplet characteristics. Biosystems Engineering 97: 333-345.

Nuyttens, D.; De Schampheleire, M.; Verboven, P.; Sonck, B. 2010. Comparison between indirect and direct spray drift assessment methods. Biosystems Engineering. 105: 2-12.

Nuyttens, D.; De Schampheleire, M.; Baetens, K.; Brusselman, E.; Dekeyser, D.; Verboven, P. 2011. Drift from field crop sprayers using an integrated approach: results of a 5 year study. Transactions of the ASABE 54: 403-408

Perfect, E.; Bird, N.; Rieu, M. 1992. Generalizing the fractal model of soil structure: the pore-solid fractal approach. Geoderma 88: 137-164.

Steel, R.G.D; Torrie, J.H. 1980. Principles and Procedures of Statistics: biometrial approach. McGraw-Hill, New York, NY, USA.

Taguas, F.J.; Martín, M.A.; Perfect, E. 1999. Simulation and testing of self-similar structures, for soil particle-size distributions using iterated function systems. Geoderma 88: 191-203.

Turcotte, D.L. 1992. Fractals and Chaos in Geology and Geophysics. Cambridge University Press, Cambridge, UK.

Tyler, S.W.; Wheatcraft, S.W. 1992. Fractal scaling for soil particlesize distributions: analysis and limitations. Soil Science Society of America Journal 56: 362-369.

Teske, M.E.; Thistle, H.W.; Mickle, R.E. 2000. Modeling finer droplet aerial spray drift and deposition. Applied Engineering in Agriculture 16: 351-357.

Womac, A.R. 1999. Measurements variations in reference sprays for nozzle classification. Transaction of ASAE 42: 609-616.

Womac, A.R. 2001. Atomization characteristics of high-flow variableorifice flooding nozzles. Transaction of ASAE 44: 463-471.

Zhu, H.; Reichard, D.L.; Fox, R.D.; Brazee, R.D.; Ozkam, H.E. 1994. Simulation of drift of discrete size of water droplets from field sprayers. Transaction of ASAE 37: 1401-1407. 